\title{
Determinação dos Valores de Energia e do Balanço de Nitrogênio de Alguns Alimentos para Leitões na Fase Inicial
}

\author{
Teresinha Marisa Bertol ${ }^{1}$, Jorge Vítor Ludke ${ }^{2}$
}

\begin{abstract}
RESUMO - Este trabalho foi realizado para obter valores de energia digestível (ED) e metabolizável (EM) de quatorze alimentos, em cinco experimentos, utilizando-se 144 leitões com 28 dias de idade e peso médio de 9,42 $\pm 0,76 \mathrm{~kg}$. O teor de energia digestível (ED) e o de energia metabolizável (EM) foram determinados por intermédio do método de coleta total de fezes e urina. As fontes de proteína provenientes do leite foram superiores aos subprodutos da soja, com relação à digestibilidade da energia e da proteína. Entre os subprodutos da soja, a proteína concentrada e a proteína texturizada apresentaram os maiores valores de digestibilidade da energia e a soja integral extrusada, os menores. A digestibilidade da matéria seca e da energia do milho e do farelo de soja com 46,5\% de proteína bruta foi semelhante à observada em avaliações com suínos adultos, indicando que a capacidade dos leitões jovens para digerir estes dois alimentos foi semelhante à dos suínos adultos. Houve redução da relação EM/ED, em virtude do aumento do teor de proteína e do desequilíbrio entre os aminoácidos da dieta e diminuição da relação entre energia bruta e $\mathrm{N}$ excretados na urina, com aumento do teor de proteína da dieta e vice-versa. Estes dados indicam a necessidade de se desenvolverem fatores de correção para EM específicos para diferentes grupos de alimentos e condições de experimentação.
\end{abstract}

Palavras-chave: digestibilidade, metabolismo, suínos

\section{Determination of Energy Values and Nitrogen Balance of Some Feeds for the Young Pigs}

ABSTRACT - The objective of this work was to determine the digestible (DE) and metabolizable (ME) energy values of some feeds for weaned pigs. Fourteen feeds were evaluated in five experiments, using 144 piglets with an average initial weight of $9.42 \pm 0.76 \mathrm{~kg}$ at 28 days of age. The DE and ME contents were determined by means of the total collection of feces and urine method. The protein sources from milk had higher energy and protein digestibility than soybean by products. Among these, concentrated protein and textured protein had the highest energy digestibility, and full fat extruded soybean had the smallest. The dry matter and energy digestibility values obtained for corn and soybean meal with $46.5 \%$ crude protein were similar to the values obtained for adults pigs, indicating that the capacity of piglets to digest these two feeds did not differ from adults swine. There was a reduction in the ME/DE ratio with increasing protein levels and with unbalance among dietary amino acids. The gross energy to $\mathrm{N}$ excreted in the urine ratio was reduced when dietary protein was increased and vices versa. These data indicate the need to determine a correction factor for the EM values, specific to the different groups of feeds and experimental conditions.

Key Words: digestibility, metabolism, swine

\section{Introdução}

O ajuste das dietas, de acordo com as exigências nutricionais dos suínos, passa pela correta avaliação destas exigências e do valor nutricional dos alimentos, o que está relacionado, entre outros fatores, à capacidade digestiva dos suínos nas diferentes faixas etárias. O desenvolvimento da capacidade digestiva dos leitões após o nascimento está associado à idade cronológica, à composição da dieta, à idade ao desmame e ao nível sanitário do rebanho, entre outros. A alteração do nível e da atividade das enzimas digestivas no suíno é mais acentuada nos primeiros 42 dias de vida, mas continua a evoluir após esta idade. Conseqüentemente, a capacidade dos suínos para digerir diferentes tipos de alimentos varia com a idade; por conseguinte, os valores de digestibilidade das frações dos alimentos, bem como os valores de energia digestível e metabolizável, variam com a idade. No que se refere aos alimentos de origem vegetal, a capacidade digestiva do suíno aumenta com a idade, em função da elevação da produção e da atividade da maioria das enzimas digestivas. $\mathrm{O}$ aumento da fermentação bacteriana dos resíduos não-digeridos no intestino grosso também contribui para o melhor aproveitamento dos alimentos nos suínos adultos. Por outro lado, a digestibilidade dos subprodutos do leite que contêm lactose é reduzida 
com a idade, como consequiência da diminuição do nível de lactase intestinal. O aumento do coeficiente de digestibilidade das várias frações dos alimentos, de acordo com a idade, foi observado por BURLACU et al. (1978) e NOBLET e SHI (1994). NOBLET e SHI (1994) constataram que este efeito é mais acentuado em dietas menos digestíveis ou com alto teor de fibra. MOREIRA et al. (1994) determinaram os valores de energia digestível e energia metabolizável de alguns alimentos com leitões de 21 dias de idade e observaram que a energia digestível do milho foi inferior aos valores constantes nas tabelas de composição de alimentos. O processamento ao qual são submetidos os subprodutos industriais é outro fator que altera a disponibilidade dos nutrientes, variando o valor nutricional destes alimentos. Além disso, nas tabelas de composição de alimentos, nem sempre são encontrados valores de energia de determinados alimentos utilizados exclusivamente em dietas para leitões, como os subprodutos do leite e alguns subprodutos da soja. Em vista disso, este trabalho foi realizado com o objetivo de determinar valores de energia digestível e energia metabolizável de alguns alimentos utilizados em dietas para leitões na fase de creche.

\section{Material e Métodos}

Quatorze alimentos foram avaliados quanto aos valores de energia, utilizando-se leitões de 28 dias de idade. Nos experimentos de 1 a 4 , foram utilizados oito leitões (unidades experimentais) para cada alimento e para as dietas referências (DR). No experimento 5, foram utilizados seis leitões para cada alimento e para a DR, totalizando 144 leitões nos cinco experimentos. A composição química também foi determinada para caracterização dos alimentos em estudo.

A dieta referência (DR), à base de milho e farelo de soja e com $15 \%$ de soro de leite em pó (Tabela 1), foi fornecida simultaneamente com as dietas contendo os alimentos em estudo. Estes substituíram 30\% da DR, com exceção do OBS, o qual substituiu $15 \%$ da DR. As dietas foram fornecidas à vontade durante o período de sete dias de adaptação às dietas e gaiolas. No final deste período, a quantidade média consumida por animal por dia em cada bloco foi determinada. Esta quantidade foi fornecida ao animal mais leve do bloco e, para os outros, foi aumentada proporcionalmente ao peso metabólico. Após o período de adaptação, foi iniciado o período de coleta (quatro dias), cujo início e final foram determinados por intermédio de marcador fecal $(0,5 \%$ de óxido férrico). Foi utilizado o método de coleta total de fezes e urina, conforme metodologia descrita por FIALHO (1989), porém, a urina não foi diluída a volume constante para todos os animais, por ocasião da coleta. A urina foi coletada em um recipiente contendo $20 \mathrm{~mL}$ de $\mathrm{HCl}$ e, diariamente pela manhã, foi homogeneizada, medida e retirada uma amostra de $50 \mathrm{~mL}$, formando uma amostra composta dos quatro dias de coleta. As fezes foram coletadas diariamente, sendo que no final de cada experimento a quantidade total por animal foi pesada, homogeneizada e retirada uma amostra, a qual foi submetida à pré-secagem em estufa a $55^{\circ} \mathrm{C}$.

O milho e o farelo de soja avaliados foram submetidos à moagem em moinho de martelo, com peneira de $7 \mathrm{~mm}$. As análises de composição química e energia bruta (EB) dos alimentos, das fezes e da urina foram realizadas no laboratório de Nutrição Animal do CNPSA, de acordo com a ASSOCIATION OF OFFICIAL ANALYTICAL CHEMISTS - AOAC (1984) e PARR INSTRUMENTS CO. (1984).

Os leitões foram desmamados com 21 dias de idade e, após uma semana, transferidos para gaiolas metabólicas de metal, onde foram alojados, individualmente, em uma sala climatizada, com temperatura de aproximadamente $22^{\circ} \mathrm{C}$. O delineamento experimental utilizado foi o de blocos casualizados. A distribuição dos leitões nos blocos foi feita de acordo com o peso inicial. O peso médio inicial (PMI) dos leitões e os alimentos testados em cada experimento estão na Tabela 2.

Os dados de peso médio ao final do experimento (PMF), ganho de peso total (GPT), consumo diário de alimento (CDA), coeficiente de digestibilidade aparente da matéria seca da dieta (CDAMS), coeficiente de digestibilidade aparente da proteína bruta da dieta (CDAPB), relação entre energia digestível (ED) e energia bruta $(\mathrm{EB})$ da dieta $(\mathrm{ED} / \mathrm{EB})$, relação entre energia metabolizável (EM) e energia digestível da dieta (EM/ED), energia bruta da urina (EBU), nitrogênio da urina (NU) e relação entre EBU e NU (EBU/NU) foram submetidos à análise estatística por intermédio do procedimento GLM do SAS (1990). As médias foram comparadas por meio do teste $t$, considerando-se nível de $10 \%$ como nível mínimo de significância.

\section{Resultados e Discussão}

Os dados de PMI, PMF, GPT e CDA encontramse na Tabela 2. Em geral, o PMF e o GPT variaram de acordo com tipo de alimento e o experimento. 
Rev. bras. zootec.

Tabela 1 - Composição da dieta referência (\%)

Table 1 - Composition of basal diet

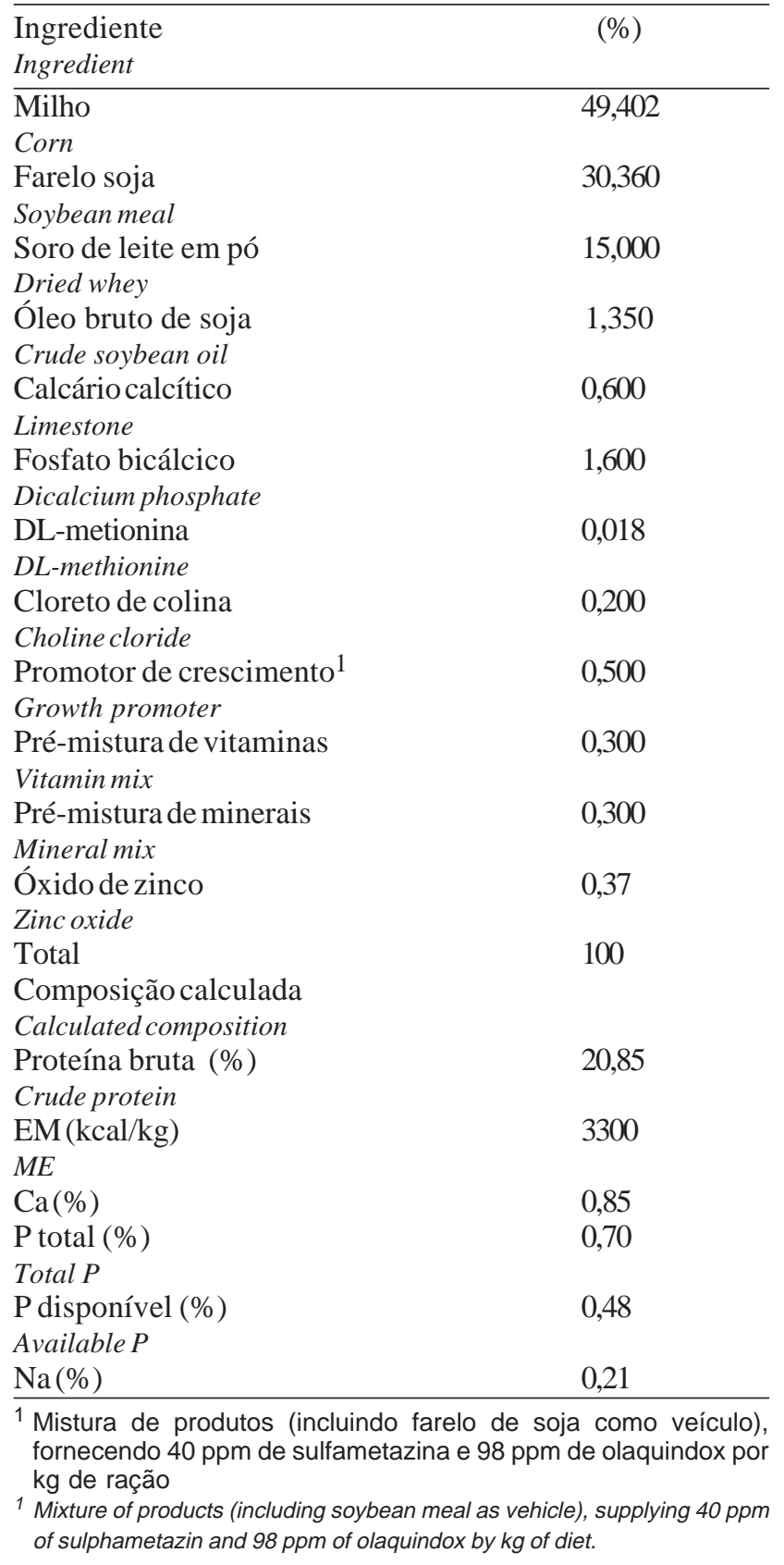

Os valores médios de ED e EM obtidos para duas partidas de milho (MI, Tabela 3 ) foram superiores em 6,5 e $9,1 \%$, respectivamente, aos obtidos com leitões desmamados aos 21 dias de idade (MOREIRA et al., 1994) e inferiores em 4,3 e 4,4\%, respectivamente, à média de dez partidas de MI avaliadas com suínos de $50 \mathrm{~kg}$ de peso vivo (BERTOL e ZANOTTO, 1997). O CDAMS e a digestibilidade da energia (ED/EB) da dieta foram elevadas, no máximo, em $1 \%$ com a inclusão de $30 \%$ de MI, enquanto o CDAPB foi reduzido em 2,21 e 2,69\% para o MI 1 e MI 2, respectivamente, em relação à DR; entretanto, estas diferenças não foram signifi- cativas $(\mathrm{P}>0,10$, Tabela 4$)$.

Os farelos de soja (FS), com 44,5 e 46,5\% de proteína bruta (PB), apresentaram valores de ED e EM diferenciados entre si (Tabela 3). Os valores de ED e EM obtidos para o FS com 44,5\% PB foram inferiores em 3,64 e 2,55\%, respectivamente, ao apresentado no NATIONAL RESEARCH COUNCIL NRC (1998) para farelos de soja semelhantes. Para o FS com 46,5\% PB, os valores de ED e EM encontrados foram superiores em 8,39 e 3,54\%, respectivamente, aos obtidos por MOREIRA et al. (1994), com leitões de 21 dias de idade. Isto pode ser explicado pelo maior CDAMS do FS 46,5\% PB deste experimento, em comparação com o avaliado por MOREIRA et al. (1994). O CDAMS do FS com 46,5\% PB foi $2,19 \%$ superior e os valores de ED e EM foram semelhantes ao obtido com suínos de $50 \mathrm{~kg}$ de peso vivo (BERTOL e ZANOTTO, 1997). As diferenças entre os resultados obtidos por MOREIRA et al. (1994) e os deste experimento, com relação ao milho e ao farelo de soja, podem estar relacionadas ao fato de que, no trabalho daqueles autores, os leitões foram desmamados e imediatamente transferidos para as gaiolas de metabolismo, enquanto, neste experimento, os leitões foram transferidos para as gaiolas uma semana após o desmame, ou seja, após passado o período de estresse causado pelo desmame.

Com relação à lactose (LAC) e ao soro de leite em pó (SLP), os valores de energia diferiram em relação aos obtidos por DIGGS et al. (1965), os quais obtiveram $3494 \mathrm{kcal}$ ED e $3409 \mathrm{kcal}$ EM para a LAC e 3114 kcal ED e 3001 kcal EM para o SLP, com leitões de $15 \mathrm{~kg}$ de peso vivo. Os valores de ED e EM obtidos para o SLP estão ligeiramente abaixo do citado pelo INRA (NOVUS INTERNATIONAL, 1994). O CDAMS da dieta que continha $30 \%$ de LAC foi $3,30 \%$ maior $(\mathrm{P}<0,05)$ que o da DR e o CDAPB, $5,07 \%$ menor ( $\mathrm{P}<0,05$, Tabela 4$)$.

O valor de ED obtido para a caseína (CS) foi superior ao citado pelo INRA (NOVUS INTERNATIONAL, 1994) e pelo NRC (1998). A inclusão de $30 \%$ de CS na dieta provocou aumento de $4,26 \%$ no CDAMS $(\mathrm{P}<0,05), 4,55 \%$ na digestibilidade da energia $(\mathrm{P}<0,02)$ e $9,03 \%$ no CDAPB $(\mathrm{P}<0,05)$, em comparação com a DR. Isto indica que o aumento da digestibilidade da fração protéica deve ter sido o maior responsável pelo aumento da digestibilidade da energia da dieta contendo CS.

O leite desnatado em pó (LDP) apresentou alta digestibilidade da MS e da energia, em comparação com os outros alimentos avaliados. O valor de CDAMS 
Tabela 2 - Peso médio inicial (PMI) e final (PMF), ganho de peso total (GPT) e consumo diário de alimento (CDA) dos leitões por tratamento, nos experimentos de 1 a 5

Table 2 - Average initial weight (PMI), average final weight (PMF), total weight gain (GPT) and daily feed intake (CDA) in piglets by treatment, in the experiments 1 to 5

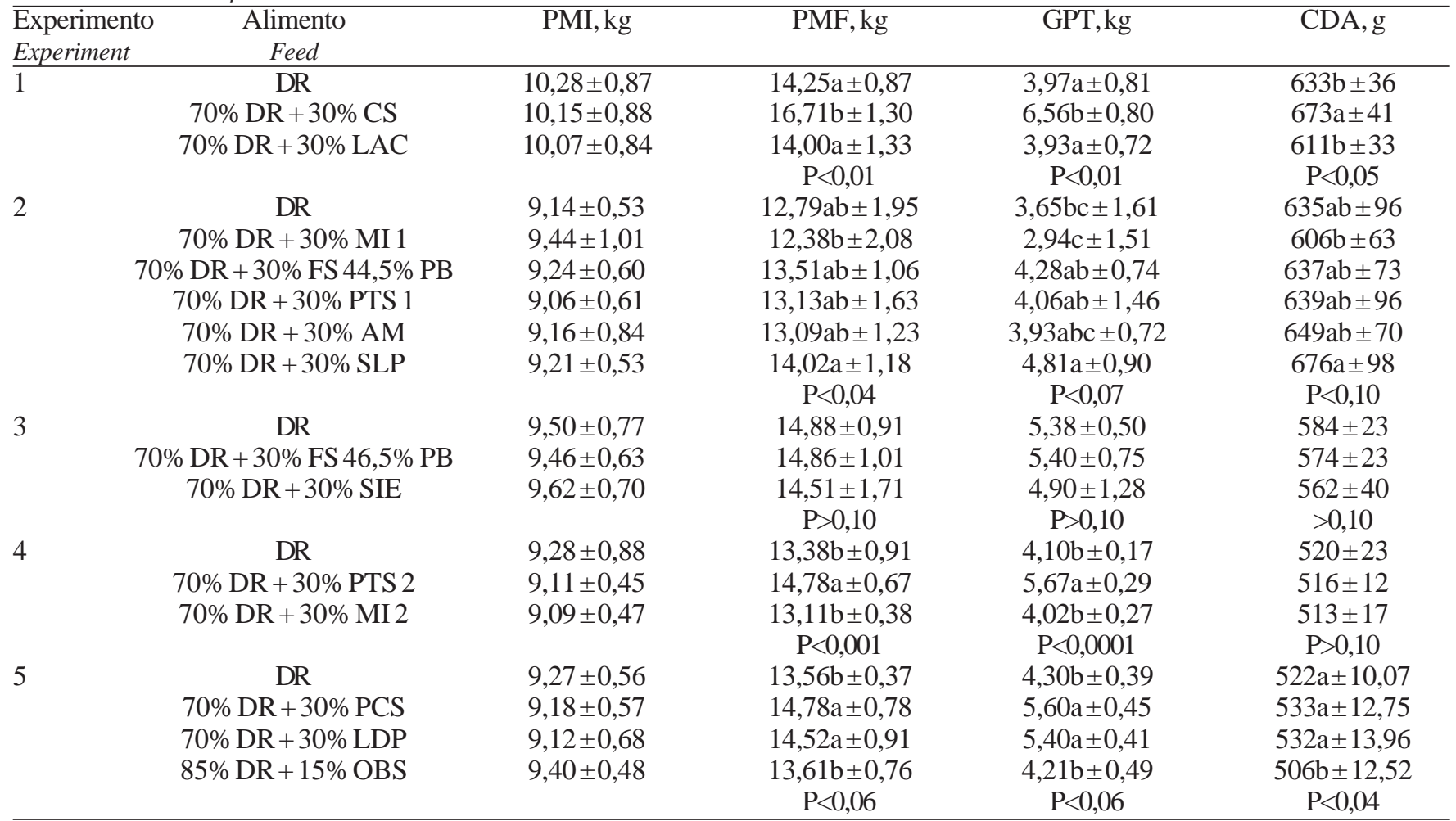

Médias, na coluna, seguidas de letras diferentes são diferentes $(P<0,10)$ pelo teste t.

Means, in a column, followed by different letters are different $(P<.10)$ by $t$ test.

№ = número do experimento (number of the experiment), DR = dieta referência (basal diet), CS = caseinato de sódio (sodium caseinate), LAC = lactose, $\mathrm{MI}=$ milho (corn), $\mathrm{FS}=$ farelo de soja (soybean meal), PTS = proteína texturizada de soja (texturized soybean protein), AM = amido de mandioca (cassava starch), SLP = soro de leite em pó (dried whey); SIE = soja integral extrusada (full-fat extruded soybeans), PCS= proteína concentrada de soja (concentrated soybean protein), LDP= leite desnatado em pó (dried skim milk), OBS = óleo bruto de soja (crude soybean oil).

superior a $100 \%$ e o de ED superior ao da EB obtido para este alimento (Tabela 3) podem ser atribuídos ao aumento da digestibilidade dos nutrientes dos demais alimentos da dieta, em razão do efeito da adição do LDP. O CDAMS, CDAPB e a digestibilidade da energia da dieta foram 6,66 ( $\mathrm{P}<0,04), 6,14(\mathrm{P}<0,07)$ e $7,23 \%(P<0,06)$ maiores, respectivamente, na dieta que continha $30 \%$ de LDP em relação à DR (Tabela 4).

A soja integral extrusada (SIE) apresentou valores de EDeEM inferiores em 13,8 e 17,6\%, respectivamente, aos resultados obtidos anteriormente com suínos de $50 \mathrm{~kg}$ de peso vivo (dados não publicados). O CDAMS foi superior ao obtido por outros autores com leitões de 4,7 e 9,7 kg de peso vivo (80,8 e 81,0\%, respectivamente, HANCOCK et al., 1995). A digestibilidade da energia da SIE foi inferior à dos FS com 44,5 e 46,5\% PB (Tabela 3). A inclusão de $30 \%$ de SIE na dieta não alterou o CDAMS, o CDAPB e a digestibilidade da energia da dieta em relação à DR (Tabela 4).
As duas proteínas texturizadas de soja avaliadas (PTS 1 e 2) apresentaram valores de ED e EM bastante diferentes entre si, mas ambas foram superiores aos FS com 44,5 ou 46,5\% PB (Tabela 3). O CDAMS e o CDAPB das dietas contendo $30 \%$ de PTS foram semelhantes entre ambas (Tabela 4), mas a digestibilidade da energia da PTS 2 foi $3,33 \%$ superior à da PTS 1 (Tabela 3). Isto sugere que o coeficiente de digestibilidade das outras frações da PTS também foi diferenciado para ambas. Era esperado que o CDAPB da dieta fosse menor para a PTS 1, em função da menor solubilidade protéica da primeira $(71,56 \%)$, comparada à segunda $(82,935 \%)$. A diferença entre os valores de ED e EM das duas PTS está parcialmente relacionada ao conteúdo de EB, o qual foi menor para a PTS 1, e ao processamento imposto a cada uma delas, sugerido pelos valores de solubilidade protéica.

A proteína concentrada de soja (PCS) apresentou altos valores de ED e EM, quando comparada aos FS e 
Rev. bras. zootec.

Tabela 3 - Valores de composição química, digestibilidade aparente da matéria seca e energia dos alimentos estudados (\% da matéria natural)

Table 3 - Chemical composition, apparent digestibility of dry matter and energy values of feeds (\% of natural matter)

\begin{tabular}{|c|c|c|c|c|c|c|c|c|c|c|}
\hline $\begin{array}{l}\text { Alimento } \\
\text { Feed }\end{array}$ & $\operatorname{MS}(\%)$ & $\mathrm{PB}(\%)$ & $\mathrm{FB}(\%)$ & $\mathrm{EE}(\%)$ & CDAMS $^{1}(\%)$ & $\mathrm{BB}$ (kcal) & $\mathrm{ED}^{1}(\mathrm{kcal})$ & $\mathrm{EM}^{1}(\mathrm{kcal})$ & $\mathrm{ED} / \mathrm{EB}$ & $\mathrm{EM} / \mathrm{ED}$ \\
\hline $\begin{array}{l}\text { Milho }^{2} \\
\text { Corn }\end{array}$ & 86,42 & 8,00 & 2,79 & 3,52 & $90,07 \pm 10,89$ & 3838 & $3332 \pm 404$ & $3261 \pm 421$ & 0,87 & 0,98 \\
\hline $\mathrm{FS} 44,5 \% \mathrm{~PB}$ & 86,15 & 44,53 & 3,86 & 2,24 & $86,63 \pm 9,58$ & 3996 & $3363 \pm 362$ & $3099 \pm 416$ & 0,84 & 0,92 \\
\hline $\mathrm{FS} 46,5 \% \mathrm{~PB}$ & 86,96 & 46,53 & 4,10 & 1,49 & $88,41 \pm 6,19$ & 4128 & $3605 \pm 236$ & $3245 \pm 265$ & 0,87 & 0,90 \\
\hline $\mathrm{CS}$ & 94,32 & 84,78 & - & 0,29 & $100,0 \pm 5,88$ & 5305 & $5058 \pm 257$ & $4613 \pm 279$ & 0,95 & 0,91 \\
\hline SLP & 92,20 & 12,40 & - & 0,56 & $91,34 \pm 5,53$ & 3618 & $3238 \pm 257$ & $3112 \pm 254$ & 0,89 & 0,96 \\
\hline LAC & 97,13 & - & - & - & $97,44 \pm 7,81$ & 3670 & $3309 \pm 333$ & $3184 \pm 355$ & 0,90 & 0,96 \\
\hline $\mathrm{AM}$ & 86,68 & - & - & - & $89,07 \pm 7$ & 3399 & $3009 \pm 302$ & $2957 \pm 296$ & 0,89 & 0,98 \\
\hline PTS $1^{3}$ & 87,34 & 48,86 & 0,82 & 0,34 & $90,92 \pm 10,08$ & 4024 & $3618 \pm 451$ & $3349 \pm 435$ & 0,90 & 0,93 \\
\hline PTS $2^{4}$ & 95,77 & 54,85 & - & 0,16 & $90,87 \pm 6,52$ & 4302 & $4006 \pm 254$ & $3778 \pm 304$ & 0,93 & 0,94 \\
\hline SIE $^{5}$ & 91,56 & 35,86 & 7,57 & 20,08 & $86,30 \pm 7,63$ & 5160 & $4106 \pm 288$ & $3819 \pm 284$ & 0,80 & 0,93 \\
\hline PCS & 93,34 & 62,44 & 3,46 & 0,40 & $94,15 \pm 1,47$ & 4436 & $4143 \pm 93,78$ & $3884 \pm 105$ & 0,93 & 0,94 \\
\hline LDP & 94,95 & 31,90 & - & 0,07 & & 4029 & $4100 \pm 352$ & $3978 \pm 327$ & 1,02 & 0,97 \\
\hline OBS & 99,98 & - & - & 96,80 & $99,14 \pm 13,07$ & 9612 & $8641 \pm 1083$ & $8548 \pm 1080$ & 0,90 & 0,99 \\
\hline
\end{tabular}

1 Média \pm desvio-padrão (average \pm standard error).

2 Média de duas amostras (average of two sample).

3 Urease (urease activity), 0,02; Grau de solubilidade protéica (GSP) (solubility of protein degree), 71,56\%.

4 Urease: 0,05 , GSP: $82,935$.

5 Urease: 0,03; GSP: 83,267\%.

$\mathrm{MS}=$ matéria seca (dry matter), PB = proteína bruta (crude protein), EE = extrato etéreo (ether extract), CDAMS = coeficiente de digestibilidade aparente da matéria seca (coeficient of dry matter apparent digestibility), EB = energia bruta (gross energy), ED = energia digestível (digestible energy) $\mathrm{EM}=$ energia metabolizável (metabolizable energy).

$\mathrm{FS}=$ farelo de soja (soybean meal), $\mathrm{CS}=$ caseinato de sódio (sodium caseinate), $\mathrm{SLP}=$ soro de leite em pó (dried whey), LAC $=$ lactose, $\mathrm{AM}=$ amido de mandioca (cassava starch), PTS = proteína texturizada de soja (texturized soybean protein), SIE = soja integral extrusada (full-fatextruded soybean), $\mathrm{PCS}=$ proteína concentrada de soja (concentrated soybean protein), LDP = leite desnatado em pó (dried skim milk), OBS = óleo bruto de soja (crude soybean oil).

à PTS 1 (Tabela 3). A digestibilidade da energia da PCS foi igual à da PTS 2, mas inferior à do LDP. A inclusão de $30 \%$ de PCS na dieta resultou em aumento de $3,89 \%$ no CDAMS $(\mathrm{P}<0,04), 4,97 \%$ no CDAPB $(\mathrm{P}<0,07)$ e $4,82 \%(\mathrm{P}<0,06)$ na digestibilidade da energia da dieta, em comparação à dieta referência (Tabela 4).

O óleo bruto de soja (OBS), contrariamente ao esperado, apresentou alto valor de CDAMS e valor de EM superior ao obtido com suínos de $50 \mathrm{~kg}$ de peso vivo (EMBRAPA, 1991), porém muito próximo ao citado no RHÔNE-POLENC ANIMAL NUTRITION (1987). Os valores de ED e EM do OBS (Tabela 3) foram superiores, também, aos encontrados por PHILLIPS e EWAN (1977), os quais obtiveram 8159 e $7800 \mathrm{kcal}$ de ED e EM por kg, respectivamente, com a inclusão de, aproximadamente, $14 \%$ OBS na dieta. A diferença entre os valores de ED e EM encontrados neste experimento e os obtidos por PHILLIPS e EWAN (1977), provavelmente, foi causada por fatores como maior valor de energia bruta do OBS utilizado neste experimento (9612 x $9410 \mathrm{kcal} / \mathrm{kg})$; maior relação EM/ED observada neste experimento $(0,99 \times 0,96)$, causada provavelmente pelo menor teor de proteína bruta $(\mathrm{PB})$ na dieta (16,36 x 37,7\%); e maior capacidade digestiva dos leitões utilizados neste experimento, os quais tinham maior peso vivo inicial que os utilizados por PHILLIPS e EWAN (1977) $(9,40$ x 5,6 kg). Este último ponto pode ser reforçado pela observação de que o CDAMS e a digestibilidade da energia da dieta aumentaram em 2,17 $(\mathrm{P}<0,04)$ e $3,61 \%(\mathrm{P}<0,07)$, respectivamente, com a inclusão de $15 \%$ OBS na dieta neste experimento (Tabela 4), enquanto, no trabalho de PHILLIPS e EWAN (1977), não houve alteração destes dois parâmetros com a inclusão do OBS na dieta.

$\mathrm{O}$ amido de mandioca (AM) apresentou valores de ED e EM (Tabela 3) inferiores aos citados pela EMBRAPA (1991), obtidos com suínos de $50 \mathrm{~kg}$ de peso vivo. A relação EM/ED, como esperado, foi bastante alta $(0,98)$, em função do baixo conteúdo de PB da dieta que continha $30 \%$ AM. A inclusão de $30 \%$ AM na dieta provocou redução de $5,73 \%$ no CDAPB $(\mathrm{P}<0,04)$ em relação à DR (Tabela 4).

Pode-se observar, neste estudo, a superioridade das fontes de proteína do leite sobre os subprodutos da soja, com relação à digestibilidade da energia e da proteína. Entre os subprodutos da soja, o tipo e a intensidade do processamento imposto levam a gran- 
Tabela 4 - Efeito da substituição parcial da dieta referência (DR) por vários alimentos sobre os valores de energia e alguns indicadores de digestibilidade e metabolizibilidade das dietas (Experimentos 1 a 5)

Table 4 - Effect of partial substitution of the basal diet (DR) by several foods on energy values and some indicators of digestibility and metabolizibility of the diets (Experiments 1 to 5$)$

\begin{tabular}{|c|c|c|c|c|c|c|c|c|c|c|}
\hline$\overline{\mathrm{N}^{\circ}}$ & $\begin{array}{c}\text { Alimento } \\
\text { Feed }\end{array}$ & $\operatorname{MS}(\%)$ & $\overline{D A M S}(\%)$ & $\mathrm{PB}(\%)$ & $\mathrm{CDAPB}(\%)$ & $\mathrm{EB}$ (kcal) & $\mathrm{ED}(\mathrm{kcal})$ & $\mathrm{EM}(\mathrm{kcal})$ & $\mathrm{ED} / \mathrm{EB}$ & $\mathrm{EM} / \mathrm{ED}$ \\
\hline \multirow[t]{4}{*}{1} & $\mathrm{DR}$ & 88,50 & $87,76 a$ & 17,16 & $86,81 b$ & 3908 & 3442 & 3337 & $0,88 \mathrm{a}$ & $0,97 \mathrm{a}$ \\
\hline & $30 \% \mathrm{DR}+30 \% \mathrm{CS}$ & 90,28 & $91,50 \mathrm{~b}$ & 38,26 & $94,65 \mathrm{a}$ & 4252 & 3910 & 3708 & $0,92 \mathrm{~b}$ & $0,95 b$ \\
\hline & $70 \% \mathrm{DR}+30 \% \mathrm{LAC}$ & 91,40 & $90,66 b$ & 12,31 & $82,41 \mathrm{c}$ & 3801 & 3422 & 3311 & $0,90 \mathrm{ab}$ & $0,97 \mathrm{a}$ \\
\hline & & & $P<0,05$ & & $\mathrm{P}<0,05$ & & & & $\mathrm{P}<0,02$ & $\mathrm{P}<0,0001$ \\
\hline \multirow[t]{7}{*}{2} & DR & 88,14 & 87,28 & 19,17 & $85,63 \mathrm{ab}$ & 3861 & 3371 & 3284 & 0,87 & 0,97 \\
\hline & $70 \% \mathrm{DR}+30 \% \mathrm{MI} 1$ & 87,81 & 87,89 & 16,47 & $83,74 b c$ & 3850 & 3373 & 3291 & 0,88 & 0,98 \\
\hline & $70 \% \mathrm{DR}+30 \% \mathrm{FS} 44,5 \% \mathrm{~PB}$ & 88,01 & 87,09 & 27,68 & $85,91 \mathrm{ab}$ & 3901 & 3387 & 3245 & 0,87 & 0,96 \\
\hline & $70 \%$ DR $+30 \%$ PTS 1 & 88,00 & 88,38 & 30,15 & $89,15 a$ & 3910 & 3424 & 3285 & 0,88 & 0,96 \\
\hline & $70 \% \mathrm{DR}+30 \% \mathrm{AM}$ & 87,45 & 87,82 & 13,94 & $80,72 c$ & 3722 & 3252 & 3176 & 0,87 & 0,98 \\
\hline & $70 \% \mathrm{DR}+30 \% \mathrm{SLP}$ & 89,88 & 88,50 & 17,23 & $84,30 \mathrm{bc}$ & 3788 & 3353 & 3254 & 0,89 & 0,97 \\
\hline & & & $P>0,10$ & & $\mathrm{P}<0,04$ & & & & $P>0,10$ & $\mathrm{P}>0,10$ \\
\hline \multirow[t]{4}{*}{3} & $\mathrm{DR}$ & 90,58 & 86,01 & 20,01 & $84,29 \mathrm{ab}$ & 3904 & 3364 & 3250 & 0,86 & $0,97 \mathrm{a}$ \\
\hline & $70 \% \mathrm{DR}+30 \% \mathrm{FS} 46,5 \% \mathrm{~PB}$ & 89,58 & 87,70 & 31,88 & $88,23 \mathrm{a}$ & 3990 & 3443 & 3253 & 0,86 & $0,94 \mathrm{c}$ \\
\hline & $70 \% \mathrm{DR}+30 \% \mathrm{SIE}$ & 90,56 & 86,88 & 24,26 & $83,57 b$ & 4179 & 3573 & 3408 & 0,85 & $0,95 b$ \\
\hline & & & $P>0,10$ & & $\mathrm{P}<0,08$ & & & & $P>0,10$ & $\mathrm{P}<0,04$ \\
\hline \multirow[t]{4}{*}{4} & DR & 90,00 & 87,47 & 18,23 & $85,41 \mathrm{ab}$ & 3997 & 3526 & 3420 & 0,88 & $0,97 \mathrm{a}$ \\
\hline & $70 \% \mathrm{DR}+30 \% \mathrm{PTS} 2$ & 91,97 & 89,12 & 29,19 & $89,06 \mathrm{a}$ & 4122 & 3676 & 3535 & 0,89 & $0,96 b$ \\
\hline & $70 \% \mathrm{DR}+30 \% \mathrm{MI} 2$ & 89,41 & 88,48 & 15,31 & $83,11 \mathrm{~b}$ & 3930 & 3480 & 3385 & 0,89 & $0,97 \mathrm{a}$ \\
\hline & & & NS & & $\mathrm{P}<0,02$ & & & & $P>0,10$ & $\mathrm{P}<0,004$ \\
\hline \multirow[t]{5}{*}{5} & DR & 89,51 & $83,34 \mathrm{c}$ & 19,42 & $83,42 \mathrm{c}$ & 3892 & 3245 & 3178 & $0,83 \mathrm{~d}$ & $0,98 \mathrm{a}$ \\
\hline & $70 \% \mathrm{DR}+30 \% \mathrm{PCS}$ & 90,84 & $86,58 b$ & 33,34 & $87,57 \mathrm{a}$ & 4051 & 3515 & 3392 & $0,87 \mathrm{abc}$ & $0,97 b$ \\
\hline & $70 \% \mathrm{DR}+30 \% \mathrm{LDP}$ & 91,38 & $88,89 \mathrm{a}$ & 23,02 & $88,54 \mathrm{a}$ & 3937 & 3502 & 3420 & $0,89 \mathrm{a}$ & $0,98 \mathrm{a}$ \\
\hline & $85 \% \mathrm{DR}+15 \% \mathrm{OBS}^{1}$ & 90,50 & $85,15 b$ & 16,36 & $85,73 a$ & 4605 & 3962 & 3897 & $0,86 \mathrm{c}$ & $0,98 \mathrm{a}$ \\
\hline & & & $\mathrm{P}<0,04$ & & $\mathrm{P}<0,07$ & & & & $\mathrm{P}<0,06$ & $\mathrm{P}<0,002$ \\
\hline
\end{tabular}

Médias, na coluna, seguidas de letras diferentes são diferentes $(P<0,10)$ pelo teste $T$.

Means, in a column, followed by different letters are different $(P<.10)$ by $T$ test.

$\mathrm{MS}=$ matéria seca (dry matter), CDAMS = coeficiente de digestibilidade aparente da MS (coeficient of DM apparent digestibility), $\mathrm{PB}=$ proteína bruta (crude protein), CDAPB = coeficiente de digestibilidade aparente da PB (coeficient of CP apparent digestibility), EB = energia bruta (gross energy), ED = energia digestível (digestible energy), EM = energia metabolizável (metabolizable energy).

№ = número do experimento (Number of the experiment), DR = dieta referência (basal diet), CS = caseinato de sódio (sodium caseinate), LAC = lactose, $\mathrm{MI}=$ milho (corn), $\mathrm{FS}=$ farelo de soja (soybean meal), $\mathrm{PTS}=$ proteína texturizada de soja (texturized soybean protein), $\mathrm{AM}=$ amido de mandioca (cassava starch), SLP = soro de leite em pó (dried whey); SIE = soja integral extrusada (full-fat extruded soybeans), PCS= proteína concentrada de soja

des diferenças na digestibilidade e, conseqüentemente, na disponibilidade dos nutrientes destes alimentos. Dessa forma, a PTS 2 e a PCS apresentaram os maiores valores de digestibilidade da energia $(93 \%) \mathrm{e}$ a SIE, o menor $(80 \%)$. No entanto, como o valor de EB da SIE é alto em função de seu elevado conteúdo de óleo, os seus valores de ED e EM ficaram bastante próximos aos da PCS e PTS 2.

Alguns pesquisadores têm observado que a eficiência de utilização dos alimentos, em termos de digestibilidade dos nutrientes, aumenta com a idade dos suínos. BURLACU et al. (1978) observaram que, para dietas com composição química semelhante, foram obtidos valores de ED 2,5 a 4,0\% superiores com leitões de 25 a $50 \mathrm{~kg}$ de peso vivo em relação aos leitões de 10 a $25 \mathrm{~kg}$. NOBLET e SHI (1994), comparando suínos com peso médio de 44, 103 e $150 \mathrm{~kg}$ de peso vivo, observaram que, com o aumento da idade, ocorre aumento do coeficiente de digestibilidade da proteína, do extrato etéreo e da fibra, o qual é mais acentuado em dietas menos digestíveis ou com alto teor de fibra. Embora o valor encontrado para a digestibilidade da MS do milho tenha sido semelhante aos resultados obtidos com animais adultos (BERTOL e ZANOTTO, 1997), os valores de ED e EM para o milho neste experimento foram inferiores aos obtidos por esses autores, devido à menor digestibilidade da energia do milho pelos leitões jovens, a qual foi de $87 \%$, comparada com $90 \%$ nos suínos de $50 \mathrm{~kg}$ de peso vivo (Tabela 3 ). No caso do FS com 46,5\% PB, os valores de ED e EM foram semelhantes aos obtidos por BERTOL e ZANOTTO (1997), em virtude de a digestibilidade da energia também ter sido muito próxima ( 87 x $86 \%$, respectivamente, Tabela 3$)$. A 
Rev. bras. zootec.

Tabela 5 - Efeito da substituição parcial da dieta referência (DR) por vários alimentos sobre alguns indicadores da metabolizabilidade das dietas (Experimentos 1 a 5)

Table 5 - Effect of partial substitution of the basal diet (DR) by several foods on some indicators of metabolizibility of the diets (Experiments 1 to 5)

\begin{tabular}{|c|c|c|c|c|c|}
\hline $\mathrm{N}^{\circ}$ & $\begin{array}{l}\text { Alimento } \\
\text { Feed }\end{array}$ & $\mathrm{PB}(\%)$ & $\mathrm{EBU}(\mathrm{kcal} / \mathrm{l})$ & $\mathrm{NU}(\mathrm{g} / \mathrm{l})$ & EBU/NU \\
\hline \multirow[t]{4}{*}{1} & $\mathrm{DR}$ & 17,16 & 123 & $8,66 b$ & $14,12 b$ \\
\hline & $70 \% \mathrm{DR}+30 \% \mathrm{CS}$ & 38,26 & 121 & $12,95 \mathrm{a}$ & $9,64 \mathrm{c}$ \\
\hline & $70 \% \mathrm{DR}+30 \% \mathrm{LAC}$ & 12,31 & 143 & $8,99 b$ & $16,21 \mathrm{a}$ \\
\hline & & & $\mathrm{P}>0,10$ & $\mathrm{P}<0,006$ & $\mathrm{P}<0,04$ \\
\hline \multirow[t]{7}{*}{2} & $\mathrm{DR}$ & 19,17 & $126 a b$ & $9,61 b$ & $13,17 b$ \\
\hline & $70 \% \mathrm{DR}+30 \% \mathrm{MI} 1$ & 16,47 & $112 \mathrm{bc}$ & $8,24 b c$ & $13,63 b$ \\
\hline & $70 \% \mathrm{DR}+30 \% \mathrm{FS} 44,5 \% \mathrm{~PB}$ & 27,68 & $155 \mathrm{a}$ & $14,71 \mathrm{a}$ & $10,82 \mathrm{c}$ \\
\hline & $70 \%$ DR + 30\% PTS 1 & 30,15 & $137 \mathrm{ab}$ & $14,21 \mathrm{a}$ & $9,75 \mathrm{~d}$ \\
\hline & $70 \% \mathrm{DR}+30 \% \mathrm{AM}$ & 13,94 & $118 b$ & $7,56 \mathrm{bc}$ & $15,81 \mathrm{a}$ \\
\hline & $70 \% \mathrm{DR}+30 \% \mathrm{SLP}$ & 17,23 & $86 c$ & $5,21 \mathrm{c}$ & $16,54 a$ \\
\hline & & & $P<0,07$ & $\mathrm{P}<0,02$ & $\mathrm{P}<0,08$ \\
\hline \multirow[t]{4}{*}{3} & $\mathrm{DR}$ & 20,01 & $76 b$ & $5,38 \mathrm{~b}$ & $14,21 \mathrm{a}$ \\
\hline & $70 \% \mathrm{DR}+30 \% \mathrm{FS} 46,5 \% \mathrm{~PB}$ & 31,88 & $114 \mathrm{a}$ & $9,92 \mathrm{a}$ & $11,56 b$ \\
\hline & $70 \% \mathrm{DR}+30 \% \mathrm{SIE}$ & 24,26 & $112 \mathrm{a}$ & 8,99a & $12,65 b$ \\
\hline & & & $\mathrm{P}<0,007$ & $\mathrm{P}<0,003$ & $\mathrm{P}<0,02$ \\
\hline \multirow[t]{4}{*}{4} & DR & 18,23 & $72 \mathrm{a}$ & $3,92 \mathrm{~b}$ & $18,59 \mathrm{a}$ \\
\hline & $70 \% \mathrm{DR}+30 \% \mathrm{PTS} 2$ & 29,19 & $63 \mathrm{a}$ & $6,34 a$ & $9,98 b$ \\
\hline & $70 \% \mathrm{DR}+30 \% \mathrm{MI} 2$ & 15,31 & $50 \mathrm{~b}$ & $2,80 \mathrm{c}$ & $17,68 \mathrm{a}$ \\
\hline & & & $\mathrm{P}<0,09$ & $\mathrm{P}<0,008$ & $\mathrm{P}<0,0001$ \\
\hline \multirow[t]{5}{*}{5} & DR & 19,42 & 38 & $4,15 b$ & $9,00 \mathrm{a}$ \\
\hline & $70 \% \mathrm{DR}+30 \% \mathrm{PCS}$ & 33,34 & 55 & $9,92 \mathrm{a}$ & $5,55 b$ \\
\hline & $70 \% \mathrm{DR}+30 \% \mathrm{LDP}$ & 23,02 & 42 & $3,88 b$ & $10,99 \mathrm{a}$ \\
\hline & $85 \% \mathrm{DR}+15 \% \mathrm{OBS}$ & 16,36 & 53 & $4,40 \mathrm{~b}$ & $10,99 \mathrm{a}$ \\
\hline & & & $P>0,10$ & $\mathrm{P}<0,0003$ & $\mathrm{P}<0,02$ \\
\hline
\end{tabular}

Médias, na coluna, seguidas de letras diferentes são diferentes $(P<0,10)$ pelo teste $T$.

Means, in a column, followed by different letters are different $(P<.10)$ by $T$ test.

$\mathrm{N}^{\circ}=$ número do experimento (Number of the experiment), $\mathrm{EBU}=$ energia bruta excretada na urina (gross energy excreted in the urine), $\mathrm{NU}=$ nitrogênio excretado na urina (nitrogen excreted in the urine).

$\mathrm{N}^{\circ}=$ número do experimento, $\mathrm{DR}=$ dieta referência (basal diet), $\mathrm{CS}=$ caseinato de sódio (sodium caseinate), $\mathrm{LAC}=$ lactose

$\mathrm{MI}=$ milho (corn), $\mathrm{FS}=$ farelo de soja (soybean meal), $\mathrm{PTS}=$ proteína texturizada de soja (texturized soybean protein), $\mathrm{AM}=$ amido de mandioca (cassava starch), SLP = soro de leite em pó (dried whey) SIE = soja integral extrusada (full-fat extruded soybeans), PCS= proteína concentrada de soja (concentrated soybean protein), LDP= leite desnatado em pó (dried skim milk), OBS = óleo bruto de soja (crude soybean oil).

diferença entre os coeficientes de digestibilidade da MS e da energia, para as várias faixas de peso, sugere que o coeficiente de digestibilidade das diferentes frações de alguns alimentos também muda com a idade. Por outro lado, a tendência de maior relação EM/ED nos animais mais jovens, observada por NOBLET e SHI (1994), não ocorreu neste experimento, quando se comparam estes dados com os dos animais adultos (BERTOL e ZANOTTO, 1997).

Em geral, o CDAPB da dieta aumentou com a elevação do nível de proteína e vice-versa, pois o $\mathrm{N}$ fecal endógeno não se altera ou tem baixa variação conforme o tipo de alimento ou a quantidade de MS consumida por um suíno em determinado peso (FRAPE e TUCK, 1979). Dessa forma, nas dietas com alto teor de $\mathrm{PB}, \mathrm{o} \mathrm{N}$ fecal endógeno representou pequena fração do $\mathrm{N}$ fecal total, reduzindo-o proporcionalmente. $\mathrm{O}$ contrário ocorreu nas dietas que continham baixos níveis de $\mathrm{PB}$.

Com o aumento do nível de PB da dieta, houve também aumento da excreção de $\mathrm{N}$ na urina (NU), aumentando a energia bruta da urina (EBU) e reduzindo a relação EM/ED das dietas (Tabelas 4 e 5). Estes dados estão de acordo com NOBLET e PEREZ (1993), os quais observaram que a relação EM/ED é reduzida em $2 \%$ para cada $1 \%$ de aumento na $\mathrm{PB}$ da dieta. Isto ocorre em função do aumento do catabolismo da proteína, que está em excesso. JUST (1982) encontrou aumento da excreção de energia na urina da ordem de $1,17 \mathrm{kcal} / \mathrm{g}$ de proteína catabolizada, ou 7,31 kcal/g N. Dessa forma, o nível de PB da dieta contribui para a variabilidade nos valores de EM dos alimentos. MAY e BELL (1971), por intermédio de uma análise de regressão envolvendo o nível de PB e os valores de ED e EM da dieta, observaram que o nível de PB da dieta contribuiu com $90 \%$ da variabi- 
lidade no valor da EM. No entanto, neste trabalho, a EBU não aumentou na mesma proporção em que se elevou o NU. A relação EBU/NU foi reduzida nas dietas em que o nível de PB foi aumentado e viceversa (Tabela 5). PHILLIPS e EWAN (1977) observaram que a excreção de energia/g $\mathrm{N}$ na urina aumentou com a inclusão de óleo bruto de soja na dieta de leitões, de 8,41 para 9,97 e 15,06 kcal/g N para dietas sem a inclusão de óleo ou com a inclusão de aproximadamente 14 e 29,6\% de óleo, respectivamente. No trabalho desenvolvido por PHILLIPS e EWAN (1977), também pode estar presente o efeito do nível de $\mathrm{PB}$ das dietas sobre a relação entre excreção de energia e $\mathrm{N}$ na urina, uma vez que o nível de PB reduziu de $37,7 \%$ na DR para $28,3 \%$ na dieta com o maior nível de inclusão de óleo. A excreção de energia por grama de $\mathrm{N}$ na urina, com a inclusão de $15 \%$ de OBS na dieta $(10,99 \mathrm{kcal} / \mathrm{g})$, foi semelhante ao obtido por esses autores $(9,97 \mathrm{kcal} / \mathrm{g})$ com a inclusão de $14 \%$ de óleo.

Outro ponto importante em relação à retenção de $\mathrm{N}$ e ao valor de EM da dieta é o balanço entre os aminoácidos, bem como sua digestibilidade. À medida que um alimento protéico substitui peso por uma dieta equilibrada em aminoácidos totais e/ou digestíveis, ocorre desequilíbrio na proporção destes. Isto provoca redução da retenção de $\mathrm{N}$, pelo aumento do catabolismo dos aminoácidos que estão em excesso, aumentando, assim, a excreção de $\mathrm{N}$ na urina e reduzindo a EM da dieta ou do alimento. O contrário ocorre quando é feita suplementação para melhorar o balanço entre os aminoácidos, de forma que a suplementação com Llisina em dietas limitantes neste aminoácido aumenta a retenção de N (FRAPE e TUCK, 1979).

Dessa forma, os valores de EM dos alimentos obtidos em dietas desequilibradas em vários nutrientes, como PB, aminoácidos e precursores de energia, provavelmente não correspondem aos valores reais de EM destes mesmos alimentos em dietas nutricionalmente equilibradas. Alguns pesquisadores sugeriram fatores de correção para a EM. DIGGS et al. (1965) observaram que a excreção média de energia por grama de NU em dietas com, no mínimo, $35 \%$ PB foi de $6,77 \mathrm{kcal}$ e utilizaram este valor multiplicando-o pelo balanço de N e subtraindo-o da EM, para obtenção da EM corrigida. MAY e BELL (1971) sugeriram multiplicar o valor da ED por 0,98 para obter o valor de EM, que corresponderia ao esperado, quando níveis normais de PB são utilizados em dietas nutricionalmente equilibradas. PHILLIPS e EWAN (1977) utilizaram o valor de $8,41 \mathrm{kcal} / \mathrm{g} \mathrm{N}$ excretado para correção da EM do óleo bruto de soja. No entanto, como observado neste estudo, a excreção de energia na urina varia consideravelmente de acordo com o tipo de alimento e a relação entre os nutrientes da dieta, particularmente a proteína. Portanto, o mesmo fator de correção não seria adequado para qualquer tipo de alimento e para diferentes condições de experimentação.

\section{Conclusões}

O presente trabalho gerou não somente valores de energia digestível e energia metabolizável de alguns alimentos que não possuem referência nas principais tabelas de composição de alimentos, como também valores diferentes dos indicados nestas tabelas, o que possibilitará obter formulações melhor ajustadas às exigências de energia dos leitões na fase pós-desmame.

Os valores de digestibilidade da matéria seca e da energia obtidos para o milho e o farelo de soja, com leitões entre 28 e 42 dias de idade, demonstram que a capacidade dos leitões para digerir estes dois alimentos difere pouco daquela dos suínos adultos.

Os subprodutos da soja com maior grau de processamento, como a proteína concentrada e a proteína texturizada, apresentaram alta digestibilidade da energia, mostrando-se superiores ao farelo de soja; contudo, a caseína e o leite desnatado em pó apresentaram valores ainda maiores, evidenciando a superioridade dos subprodutos do leite como fonte de proteína para os leitões nesta fase.

A redução da relação EM/ED com o aumento do teor de proteína e o desbalanceamento entre os aminoácidos da dieta, bem como a diminuição da relação entre energia bruta da urina e $\mathrm{N}$ da urina, com o aumento do teor de proteína da dieta e vice-versa, indica a necessidade de se desenvolverem fatores de correção para aEM, diferenciados para os vários tipos de alimentos e diferentes condições de experimentação.

\section{Referências Bibliográficas}

ASSOCIATION OF OFFICIAL ANALYTICAL CHEMISTS AOAC. 1984. Officialmethods of analysis. $14 \mathrm{ed}$. Washington, D.C. $1018 \mathrm{p}$.

BERTOL, T.M., ZANOTTO, D.L. Determinação do balanço de energia e nitrogênio de alguns alimentos para suínos. In: CONGRESSO BRASILEIRO DE VETERINÁRIOS ESPECIALISTAS EM SUÍNOS, 8, 1997, Concórdia: Anais...EMBRAPA-CNPSA, 1997. p.345-346.

BURLACU, G., ILIESCU, M., STAVRI, J. 1978. Efficiency of utilization of food energy by growing pigs. J. Agric. Sci., 90:165-172.

DIGGS, B.G., BECKER, D.E., JENSEN, A H. et al. 1965. Energy value of various feeds for the young pig. J. Anim. 
Rev. bras. zootec.

Sci., 24:555-558.

EMBRAPA. Centro Nacional de Pesquisa de Suínos e Aves 1991. Tabela de composição química e valores energéticos de alimentos para suínos e aves. 3. ed. Concórdia. 97p. (EMBRAPA-CNPSA. Documentos, 19).

FIALHO, E.T. Influence of environmental temperature on nitrogen retention apparent digestibility of protein and aminoacids and energy metabolism in growing pigs. Purdue: Purdue University, 1989, 133p. Thesis (Doctor of Philosophy) - Purdue University, 1989.

FRAPE, D.L., TUCK, M.G. 1979. A relationship between amino acid supplementation of the diet of pigs and the metabolism of N and energy. J. Agric. Sci., 92:269-272.

HANCOCK, J.D., KIM, I., HINES, R.H. et al. Effects of processing on nutrient utilization from soybeans in nursery and growing pigs. In: ANUAL MEETING OF AMERICAN ASSOCIATION OF SWINE PRACTITIONERS, 1995, Omaha, Nebraska. Proceedings... Omaha: AASP, 1995. p.167-177.

JUST, A. 1982. The net energy value of crude (catabolized) protein for growth in pigs. Lvstck. Prod. Sci., 9:349-360.

MAY, R.W., BELL, J.M. 1971. Digestible and metabolizable energy values of some feeds for the growing pig. Can. J. Anim. Sci., 51(2):271-278.

MOREIRA, I., ROSTAGNO, H.S., COELHO, D.T. et al. 1994. Determinação dos coeficientes de digestibilidade, valores energéticos e índices de controle de qualidade do milho e soja integral processados a calor. R. Soc. Bras. Zootec., 23(6):916-929.

NATIONAL RESEARCH COUNCIL - NRC. 1998. Nutrients requeriments of swine. 10. ed. Washington: National Academy of Science. 189p. (Nutrient Requeriments of Domestic Animals, 2).

NOBLET, J., PEREZ, J.M. 1993. Prediction of digestibility of nutrients and energy values of pig diets from chemical analysis. J. Anim. Sci.,71(12):3389-3398.

NOBLET, J., SHI, X.S. 1994. Effect of body weight on digestive utilization of energy and nutrients of ingredients and diets in pigs. Livstck. Prod. Sci., 37(3):323-338.

NOVUS INTERNATIONAL. 1994. Raw material compendium. Brussels. 541p.

PARR INSTRUMENTS CO. 1984. Instructions for the 1241 and 1242 adiabatic calorimeters. Moline. 29p. (Parr. Manual, 153).

PHILLIPS, B.C., EWAN, R.C. 1977. Utilization of energy of milo and soybean oil by young swine. J. Anim. Sci., 44(6):990-997.

RHÔNE-POLENC ANIMAL NUTRITION. 1987. Tables AEC: recomendações para a nutrição animal. 5.ed. Paris. 86p.

SAS INSTITUTE INC. 1990. SAS user's guide: statistics, version 6.04. Cary. 956p.

Recebido em: 13/08/98

Aceito em: 01/06/99 